\title{
Analysis on the Effectiveness of Parental Stress and Aggressive Group Intervention in Preschool Disabled Children
}

\author{
Samuel Dinakaran S ${ }^{1}$, A. Julie Sandra ${ }^{2}$ \\ ${ }^{1}$ Assistant Professor, Occupational Therapy, Department of Therapeutics, National Institute for Empowerment of Persons with Multiple \\ Disabilities, Chennai, India \\ samuel1983k@gmail.com
}

${ }^{2}$ Speech Language Pathologist, SRM Medical College \& Research Institute, Chennai, India

\begin{abstract}
Background: The purpose of this study was to investigate the effectiveness of Group Interventions on perceived Stress and Aggression among parents of children with multiple disabilities who have been attending occupational therapy. Method: One-group pretest-post test design was used. 30 parents were selected based on the inclusion - exclusion criteria. Group interventions was carried out for 8 sessions, each session of 45 minutes duration.The group interventions were various strategies for Stress and Aggression management. Perceived Stress was assessed using Perceived Stress Scale and Aggression was assessed using Buss Perry Aggression Questionnaire - Short Form (Tamil) Results: The results indicated that there was a significant difference between the pretest and posttest scores in Perceived Stress Scale and Buss Perry Aggression Questionnaire- Short Form (Tamil). Conclusion: The finding emphasized that the group interventions reduced the level of Stress and Aggression among parents of children with multiple disabilities. Conduction of such group intervention can improve the mental health of parents of children with multiple disabilities.
\end{abstract}

Keywords: Perceived stress, Aggression, Group intervention, Multiple Disabilities

\section{Introduction}

Parents of children with Multiple Disabilities tend to report higher rates of stress and aggression. Families who have a disabled child are exposed to larger amount of stress when put next to alternative families. Also, parents face problem with accepting the children's disability. Children who have disabilities cause stress on the family as family contains a primary responsibility for them. Stress is the body's negative reaction to vast pressure or the other force imposed on a person. Stress is associated with individuals' inappropriate response to vast pressure.

When a child with one or more disabilities is born into a family or when parents receive the diagnosis of their child's disability, they often experience a range of emotions (e.g., shock, grief, anger) that are somewhat similar to those experienced upon learning about the death of a loved one (Kandel and Merrick, 2003).

Parents of children with disabilities tend to experience challenges at certain points of transition during the early childhood years (e.g., hospital to home, entry to early intervention programs, movement from early intervention to preschool programs, movement from preschool to kindergarten) (Malone and Gallagher, 2008, 2009)

Out-of-the-ordinary time demands might stack the odds against families of children with multiple disabilities. Parents may invest more time and energy in the difficult method of accessing and navigating supports.

Stress management program consists of increasing knowledge in stress, relaxation training, and identification of dysfunctional thoughts, cognitive restructuring, problem solving and assertiveness skills training.

Anger is an emotion whereas aggression is behavior which could occur as result of anger. Aggression is one of the behaviors mostly experienced in stressful situations. It is a strong feeling of distress in reaction to a specific provocation.

The Group interventions aim to assist individuals modify their self-image, easily express themselves, express their thoughts and ideas appropriately and consequently increase their self-esteem

Weaknesses and shortcomings impacts in the anger management cause personal distress and interpersonal relationships destruction that lead to impairment of general health, incompatibility and harmful outcomes as well as aggressive behavior. In this regard, present study tried to test group intervention program for stress and aggression among parents of children with multiple disabilities.

\section{Materials \& Methods}

\subsection{Participants}

The present research is a study with one group pretest posttest design. The sample consisted of 30 parents of children with multiple disabilities. 23 mothers \& 7 fathers participated in the study. Informed consent was obtained from parents before the actual intervention was initiated. 


\section{Sampling criteria}

\section{Inclusion criteria}

- Parents of children with multiple disabilities

- Age between 20 to 45 years

- Attending Occupational Therapy

- Expressed willingness to participate in the study

\section{Exclusion Criteria}

- Parents who had difficulty to understand Tamil or English

- Parents who are on treatment for anger and stress

\subsection{Instruments}

Perceived Stress Scale (PSS): The PSS (Cohen S, 1983) is a 10-item questionnaire to measure the self-reported level of stress in the respondents by assessing feelings and thoughts during the last month. Each item is scored from 0 (never) to 5 (very often) with a range of 0 to 40 for the total score of the scale. A higher level of stress is indicated by higher scores on this scale. Six items of the PSS-10 measure stress and 4 items measure coping strategy to stress.

Buss Perry Aggression Questionnaire - Short Form (BPAQ ST) - Tamil version - The Tamil version of Buss Perry Aggression Questionnaire has been found to be reliable \& discriminant validity has been established.(Dinakaran S, 2019). This scale consists of 12 Likert type items rated on a 6-point ordinal scale. The BPAQ-SF is organized into four scales: Physical Aggression (PA, 3 items), Verbal Aggression (VA, items), Anger (A, 3 items), and Hostility (H, 3 items)

\subsection{Procedure}

Participants were administered Perceived stress scale (PSS) and Buss Perry Aggression Questionnaire - Short Form (Tamil). The group interventions consisted of 8 sessions, the focus of each of the session are as follows:

First Session: Introduction about Stress and Anger, its causes and effects.

Second Session: Cognitive errors, Types of Stressors.

Third Session: Coping Skills for Stress Management

Fourth Session: Identifying various Triggers of Anger, Time Management

Fifth Session: Strategies for Stress and Anger management Sixth Session: Problem solving, practical session on Relaxation Techniques (Mental imagery)

Seventh Session: Assertiveness, Submissive and Aggressive behavior

Eighth Session: Review of sessions, Handouts given

At the end of each session, homework assignment was given for next session. After the intervention sessions, the post-test was taken.

\section{Results}

Paired t test was used to compare the means of pretest and posttest scores of both Perceived stress scale and Buss Perry Aggression Questionnaire - Short Form.

Table 1: Pretest posttest Stress scores

\begin{tabular}{|c|c|c|c|c|c|}
\hline \multicolumn{6}{|c|}{ Paired Samples Statistics } \\
\hline & & Mean & $\mathrm{N}$ & Std. Deviation & Std. Error Mean \\
\hline \multirow{2}{*}{ Pair 1} & Pretest & 26.5000 & 30 & 9.10381 & 1.66212 \\
\hline & Posttest & 24.4333 & 30 & 9.04656 & 1.65167 \\
\hline
\end{tabular}

Table 2

\begin{tabular}{|c|c|c|c|c|}
\hline \multicolumn{5}{|c|}{ Paired Samples Correlations } \\
\hline & & $\mathrm{N}$ & Correlation & Sig. \\
\hline Pair 1 & Pretest and Posttest & 30 & .975 & .000 \\
\hline
\end{tabular}

Table 3: Comparison of means of pretest and posttest (Perceived stress scale scores)

\begin{tabular}{|c|c|c|c|c|c|c|c|c|c|}
\hline \multicolumn{10}{|c|}{ Paired Samples Test } \\
\hline & & \multicolumn{5}{|c|}{ Paired Differences } & \multirow{3}{*}{$\mathrm{t}$} & \multirow{3}{*}{ df } & \multirow{3}{*}{$\begin{array}{c}\text { Sig. } \\
\text { (2-tailed) }\end{array}$} \\
\hline & & \multirow{2}{*}{ Mean } & \multirow{2}{*}{\begin{tabular}{|c|} 
Std. \\
Deviation
\end{tabular}} & \multirow{2}{*}{$\begin{array}{l}\text { Std. Error } \\
\text { Mean }\end{array}$} & \multicolumn{2}{|c|}{ 95\% Confidence Interval of the Difference } & & & \\
\hline & & & & & Lower & Upper & & & \\
\hline Pair1 & Pretest - Posttest & 2.06667 & 2.01603 & .36807 & 1.31387 & 2.81946 & 5.615 & 29 & .000 \\
\hline
\end{tabular}

As seen in Table 3, a statistically significant difference was seen between stress scores in pretest before intervention and post test after intervention. $\mathrm{P}<.001$, which shows it is highly significant.

Table 4

\begin{tabular}{|c|c|c|c|c|c|}
\hline \multicolumn{9}{|c|}{ Paired Samples Statistics } \\
\hline \multicolumn{2}{|c|}{} & Mean & $\mathrm{N}$ & Std. Deviation & Std. Error Mean \\
\hline \multirow{2}{*}{ Pair 1 } & Pretest & 33.4333 & 30 & 14.68211 & 2.68057 \\
\cline { 2 - 6 } & Posttest & 30.4333 & 30 & 13.57148 & 2.47780 \\
\hline
\end{tabular}

Table 5

\begin{tabular}{|c|c|c|c|c|}
\hline \multicolumn{5}{|c|}{ Paired Samples Correlations } \\
\hline & & $\mathrm{N}$ & Correlation & Sig. \\
\hline Pair 1 & Pretest and Posttest & 30 & .799 & .000 \\
\hline
\end{tabular}

Table 6: Paired Samples Test

\begin{tabular}{|c|c|c|c|c|c|c|c|c|}
\hline & \multicolumn{5}{|c|}{ Paired Differences } & \multirow{3}{*}{$\mathrm{T}$} & \multirow{3}{*}{ df } & \multirow{3}{*}{$\begin{array}{c}\text { Sig. } \\
\text { (2-tailed) }\end{array}$} \\
\hline & \multirow{2}{*}{ Mean } & Std. & Std. Error & \multicolumn{2}{|c|}{ 95\% Confidence Interval of the Difference } & & & \\
\hline & & Deviation & Mean & Lower & Upper & & & \\
\hline Pair 1|Pretest - Posttest & 3.00000 & 9.01722 & 1.64631 & -36709 & 6.36709 & 1.822 & 29 & .079 \\
\hline
\end{tabular}


As seen in Table 5, a statistically significant difference was seen between aggression scores in pretest before intervention and post test after intervention. $\mathrm{P}<.001$, which shows it is highly significant. The t-test showed that after the group intervention, the parents mean stress and aggression score significantly lower. This result shows that aggression is clearly decreased among parents that participated in the group intervention.

\section{Discussion}

The current study was conducted to investigate effectiveness of group intervention on stress and aggression. Based on this finding, group intervention reduces perceived stress and aggression among parents of children with multiple disabilities. This result is consistent with some prior researches.

Harris et al (2015) investigated the influence of stress management on sixty-four educators in two middle schools. Intervention participants had significantly improved scores on distress tolerance. Gawrysiak et al. (2018)showed that Mindfulness-Based Stress Reduction caused a decline in perceived stress. Stress management helps individual to recognize the situation which causes anxiety and stress, then they learn coping strategies to cope with stress. This process leads to reduce Stress among parents who encounter obstacle during early child development in diverse aspects.

Dehghan et al. (2006) investigated the influence of stress management in reducing of aggressiveness among students. They found that there were significant differences in perand post- test scores for all aggression components in experimental group

There is already some evidence to suggest that certain variables could be important in reducing aggressive behaviors, such as parental education and the capacity for inhibitory control, both of which have been linked to aggressive behaviors, particularly in adolescents (Raaijmakers et al.).This study shows that group interventions play an important role in the reduction of Stress and Aggression among parent of children with Multiple Disabilities.

\section{Conclusion}

This study examined the effectiveness of group intervention on stress and anger among parents of children with multiple disabilities. The results indicated that group interventions decreased stress and aggression significantly among participants who took part in the study. Studying with samples from different aggression levels and different backgrounds could provide a broader picture on the effectiveness of group interventions on stress and aggression.

Therefore, the results of current and previous research emphasize that the intervention program aimed to reduce the stress and aggression of parents who have children with multiple disabilities is necessary. Stress and aggression management interventions are crucial for Parents' of Children with Multiple Disabilities.

\section{Conflict of interest}

There was no conflict of interest

\section{References}

[1] Abbasian F , Najimi A , Ghasemi Gh , et al Effectiveness of Stress Management Training by

[2] Cognitive-Behavioral Method in Women with Depression. J Health System Res 2013; 8(6): 1050- 57. [in Persian]

[3] Butcher PR, Wind T, Bouma A. Parenting stress in mothers and fathers of a child with a hemiparesis: sources of stress, intervening factors and longterm expressions of stress. Child: care, health and development. 2008 Jul;34(4):530-41.

[4] Antony M, Ironson G, Eshnaiderman N. A Practical Guide stress management program utilizing cognitivebehavioural approach. Translator: Alemohammad J, Jukar S, Neshatdost H. 1th ed: Esfahan: Publications Academic Jihad; 2009: 48-64.[in Persian]

[5] Simons JS, Gaher RM. The Distress Tolerance Scale: Development and validation of a self-report measure. Motivat Emot 2005; 29(2): 83-102.

[6] Fives CJ, Kong G, Fuller JR, DiGiuseppe R. Anger, Aggression, and Irrational Beliefs in Adolescents. Cognitive therapy and research 2011; 35(3): 199- 208.

[7] Samuel Dinakaran, Standardization of Buss Perry Aggression Questionnaire- Short Form (BPAQ-ST) Tamil version in chennai population, JETIR June 2019, Volume 6, Issue 6

[8] Firat S, Diler RS, Avci A, Seydaoglu G. Comparison of psychopathology in the mothers of autistic and mentally retarded children. Journal of Korean medical science. 2002 Oct;17(5):679

[9] Sandmire, D. A., Gorham, S. R., Rankin, N. E., \& Grimm, D. R. (2012). The influence of art making on anxiety: A pilot study. Art Therapy: Journal of the American Art Therapy Association, 29(2), 68-73. doi:10.1080/07421656.2012.683748

[10] Steer, R. A., Kumar, G., Pinninti, N. R., \& Beck, A. T. (2003). Severity and internal consistency of selfreported anxiety in psychotic outpatients. Psychological Reports, 93, 1233-1238. doi:10.2466/pr).2003.93.3f.1233

[11] Crawford JR, Henry JD. The Depression Anxiety Stress Scales (DASS): normative data and latent structure in a large non-clinical sample. $\mathrm{Br} J$ Clin Psychol. 2003;42(Pt 2):111-31. doi: 10.1348/014466503321903544. [PubMed: 12828802]

[12] Clarke GN, Lewinsohn PM, Hops H. Cognitivebehavioral group treatment of depression in adolescents. Behav Ther. 1990; 21:385- 401. 